\title{
Active Role of Women in Disaster Prone Areas
}

\author{
Ratnanik, Yulinda Erma Suryani \\ Universitas Widya Dharma Klaten \\ ratnanik.wa@gmail.com
}

\section{Article History}

accepted 31/08/2020

approved 22/09/2020

published 28/10/2020

\begin{abstract}
Indonesia is a country that has two (2) seasons, namely the rainy season and the dry season. Klaten Regency is close to Mount Merapi, east of the Klaten area close to the Dengkeng River and its tributaries. Disaster management law No. 4 of 2007 article 4 paragraph c states that ensuring the implementation of disaster management in a planned, integrated, coordinated and comprehensive manner and respecting local culture. This study discusses the higher vulnerability of women compared to men, so that it requires handling that requires more active roles of women residents or volunteers. The aim of this research is to see how active women's roles are in disaster disasters and what roles women play in the context of disasters. From the results of the study it can be concluded that the active role of women in disaster-prone areas in Klaten Regency has begun to be trained. Evidenced by joining the Disaster Risk Reduction Organization (OPRB) in Klaten.
\end{abstract}

Keywords: Disaster, Women, Role

\begin{abstract}
Abstrak
Indonesia merupakan Negara yang mempunyai dua (2) musim, yaitu musim hujan dan musim kemarau. Kabupaten Klaten berdekatan dengan gunung merapi, sebelah timur daerah Klaten yang dekat dengan aliran Sungai Dengkeng dan anak-anak sungainya. Undang-undang penanggulangan bencana No.4 tahun 2007 pasal 4 ayat c menyatakan bahwa menjamin terselenggaranya penanggulangan bencana secara terencana, terpadu, terkoordinasi, dan menyeluruh serta menghargai budaya lokal. Pada kajian ini membahas tentang kerentanan perempuan lebih tinggi dibanding dengan laki-laki, sehingga membutuhkan penanganan yang lebih terutama membutuhkan peran aktif perempuan warga masyarakat ataupun relawan perempuan. Tujuan yang ingin dicapai dalam penelitian ini adalah untuk mengetahui bagaimana peran aktif perempuan di kawasan rawan bencana serta peran apa saja yang sudah dilakukan perempuan dalam rangka pengurangan risiko bencana. Dari hasil penelitian dapat diambil kesimpulan bahwa peran aktif perempuan di daerah rawan bencana di Kabupaten Klaten sudah mulai terlatih. Terbukti dengan ikut bergabung pada Organisasi Pengurangan Risiko Bencana (OPRB) di Klaten.
\end{abstract}

Kata kunci: Bencana, Peran, Perempuan

Social, Humanities, and Education Studies (SHEs): Conference Series https://jurnal.uns.ac.id/shes 


\section{PENDAHULUAN}

Indonesia merupakan Negara yang mempunyai dua (2) musim karena terletak di daerah tropis, yaitu musim hujan dan musim kemarau. Musim hujan di Indonesia biasanya terjadi pada Bulan Oktober sampai Bulan Maret sedangkan musim kemarau terjadi pada Bulan April sampai Bulan September. Saat ini Indonesia mengalami musim hujan. Hampir setiap hari wilayah Indonesia diguyur hujan. Dan setiap hari pula mendengar berita tentang banjir akibat luapan sungai terjadi di seluruh wilayah Indonesia. Di dua bulan pertama tahun 2020, sudah terdapat beberapa berita kejadian banjir bandang yang melanda seluruh wilayah Indonesia, termasuk terjadi juga di Kabupaten Klaten.

Setiap musim penghujan Kabupaten Klaten selalu mengalami bencana banjir, terutama daerah yang dekat dengan aliran Sungai Dengkeng dan anak sungainya. 78 desa tercatat dari 11 kecamatan pada wilayah Klaten masuk dalam kategori rawan bencana banjir (Solo Pos, Januari 2020), mayoritas berada pada sisi wilayah selatan Kabupaten Klaten. Selain daerah rawan bencana banjir, ada sejumlah desa juga masuk kategori kawasan rawan tanah longsor dan beberapa tanggul rawan jebol. Empat desa di Kecamatan Bayat Kabupaten Klaten yang masuk dalam kawasan rawan bencana banjir.

Bencana alam dapat menganggu perekonomian dan sosial kemasyarakatan. Akibat yang ditimbulkan berbagai bencana alam baik itu banjir, tanah longsor, kekeringan, tsunami, gempa bumi, maupun letusan gunung berapi mempunyai dampak yang serius terhadap kehidupan masyarakat dan lingkungannya. Pada daerah bencana tersebut selalu dibutuhkan kesiapsiagaan untuk mengevakuasi korban bencana, pendistribusian bahan makanan, penyediaan tempat MCK serta kegiatan yang lain yang dibutuhkan oleh korban bencana. Dalam konteks ini, peran aktif tidak hanya dari warga laki-laki saja tetapi dari perempuan warga sekitar dan relawan perempuan sangat dibutuhkan untuk membantu dalam penanganan korban.

Undang-undang penanggulangan bencana no.4 tahun 2007 pasal 4 ayat c menyatakan bahwa menjamin terselenggaranya penanggulangan bencana secara terencana, terpadu, terkoordinasi, dan menyeluruh serta menghargai budaya lokal. Dari Undang-undang tersebut dituntut peran aktif baik laki-laki maupun perempuan terutama warga masyarakat yang menduduki posisi penting atau berada di garis depan saat bencana terjadi dalam rangka pengurangan risiko bencana. Dalam konteks kebencanaan, peran aktif perempuan dalam berpartisipasi sangat efektif jika didukung oleh pengetahuan tentang pengurangan risiko bencana dan bagaimana menangani korban yang ada. Karena salah satu kelompok yang rentan ketika terjadi bencana adalah perempuan (ESCAP \& UNISDR, 2012; Antonius M, 2019). Kondisi perempuan terkait budaya, mobilitas serta kapasitas menyelamatkan diri perempuan menyebabkan berada di wilayah yang rentan ketika menghadapi bencana (Kibria, 2016; Antonius M, 2019).

Dampak bencana yang dialami laki-laki dan perempuan sangat berbeda dilihat dari kondisi fisik, biologis, sosial serta ekonomi. Pada kajian ini membahas tentang kerentanan perempuan lebih tinggi dibanding dengan laki-laki. Pada penelitian sebelumnya berdasarkan jenis kelamin perempuan merupakan personal yang rentan terhadap risiko bencana yang terjadi baik dalam hal kebutuhan fisik, biologis, pendampingan dari segi psikologis sehingga membutuhkan penanganan yang lebih terutama membutuhkan peran aktif perempuan warga masyarakat ataupun relawan perempuan.

Untuk itu perlu adanya kajian atau penelitian tentang Peran Aktif Perempuan Di Kawasan Rawan Bencana mengambil studi kasus Kabupaten Klaten Jawa Tengah. Tujuan yang ingin dicapai dalam penelitian ini adalah untuk mengetahui bagaimana peran aktif perempuan di kawasan rawan bencana serta peran apa saja yang sudah dilakukan perempuan dalam rangka pengurangan risiko bencana yang terjadi di 
Kabupaten Klaten. Penelitian ini diharapkan dapat memberikan manfaat kepada pemerintah dalam rangka manajemen risiko bencana secara umum serta persoalan perempuan secara khusus. Antonius, $M$ et al (2019) dalam penelitiannya menyimpulkan bahwa konsep diri perempuan di wilayah rawan bencana memandang cenderung berfikir konservatif, pernikahan dini banyak terjadi, keterbatasan akses pendidikan dan kapasitas ekonomi. Hastuti (2016) dalam penelitiannya mengambil kesimpulan bahwa peran perempuan dalam mitigasi bencana perlu ditingkatkan agar dapat menekan terjadinya kerentanan yang ditimbulkan akibat terjadinya bencana seperti kelaparan, keterbatasan akses, kehilangan tempat tinggal, merosotnya kesehatan yang dapat memicu timbulya konflik berkepanjangan pasca bencana.

\section{METODE}

Penelitian ini menggunakan jenis penelitian kualitatif dengan menggunakan metode deskriptif karena peneliti ingin mengetahui peran aktif perempuan di daerah rawan bencana secara langsung sehingga diperoleh hasil yang baru dan bermanfaat dalam rangka manajemen pengurangan resiko bencana. Tahapan yang dilakukan berkaitan dengan penelitian ini, yaitu:

1. Studi Pustaka, mengumpulkan dan mempelajari literatur serta teori-teori yang berkaitan dengan judul penelitian.

2. Pengumpulan data, Tahap pengumpulan data dilakukan untuk memperoleh datadata yang akan digunakan dalam penelitian ini dengan menggunakan teknik, yaitu: membuat kuesioner dengan google form disebarkan kepada warga masyarakat perempuan di Kabupaten Klaten.

3. Analisis dan pengelolaan data: mulai dari pengumpulan data di lapangan kemudian dilakukan penyaringan data yang sesuai dengan kebutuhan dari penelitian ini, data yang relevan berkembang sesuai dinamika masyarakat di daerah rawan bencana, selanjutnya dilakukan analisis data menurut konsep teori yang digunakan kemudian diambil kesimpulan. Cek data antara data yang diperoleh melalui kuesioner dengan hasil pengamatan secara langsung (observasi) pada keadaan daerah dan masyarakat secara langsung di lapangan.

\section{HASIL DAN PEMBAHASAN}

Lokasi penelitian di Kabupaten Klaten Provinsi Jawa Tengah terutama di daerah yang rawan bencana. Secara administrasi, Kabupaten Klaten dengan luas wilayah 655,56 kilometer persegi itu terdiri dari 26 kecamatan, 391 desa, dan 10 kelurahan. Jika dilihat dari letaknya secara geografis wikipedia, Juli 2020 tentang Kabupaten Klaten, bahwa Kabupaten Klaten terletak di antara $110^{\circ} 30^{\prime}-110^{\circ} 45^{\prime}$ Bujur Timur dan $7^{\circ} 30^{\prime}-7^{\circ} 45^{\prime}$ Lintang Selatan. Di sebelah Timur berbatasan dengan Kabupaten Sukoharjo. Di sebelah Selatan berbatasan dengan Kabupaten Gunungkidul (Daerah Istimewa Yogyakarta). Di sebelah Barat berbatasan dengan Kabupaten Sleman (Daerah Istimewa Yogyakarta) serta Kabupaten Magelang dan di sebelah Utara berbatasan dengan Kabupaten Boyolali. Wilayah Kabupaten Klaten terbagi menjadi tiga dataran yakni Sebelah Utara Dataran Lereng Gunung Merapi, Sebelah Timur Membujur Dataran Rendah, sebelah Selatan Dataran Gunung Kapur. Menurut topografi kabupaten Klaten terletak di antara gunung Merapi dan pegunungan Seribu dengan ketinggian antara 75-160 meter di atas permukaan laut yang terbagi menjadi wilayah lereng Gunung Merapi di bagian utara areal miring, wilayah datar dan wilayah berbukit di bagian selatan. Ketinggian daerah: Sekitar 3,72\% terletak di antara ketinggian 0 - 100 meter di atas permukaan laut, Terbanyak 83,52\% terletak di antara ketinggian 100 - 500 meter di atas permukaan laut, dan Sisanya 12,76\% terletak di antara ketinggian 500 - 2500 meter di atas permukaan laut. Adapun Jenis tanah pada Kabupaten Klaten terdiri dari 5 (lima) macam: 
1. Litosol: Bahan induk dari skis kristalin dan batu tulis terdapat di daerah Kecamatan Bayat.

2. Regosol Kelabu: Bahan induk abu dan pasir vulkanik termedier terdapat di Kecamatan Cawas, Trucuk, Klaten Tengah, Kalikotes, Kebonarum, Klaten Selatan, Karangnongko, Ngawen, Klaten Utara, Ceper, Pedan, Karangdowo, Juwiring, Wonosari, Delanggu, Polanharjo, Karanganom, Tulung dan Jatinom.

3. Grumusol Kelabu Tua: Bahan induk berupa abu dan pasir vulkan intermedier terdapat di daerah Kecamatan Bayat, Cawas sebelah selatan.

4. Kompleks Regosol Kelabu dan Kelabu Tua: Bahan induk berupa batuk apurnapal terdapat di daerah Kecamatan Klaten Tengah dan Kalikotes sebelah selatan.

5. Regosol Coklat Kekelabuan: Bahan induk berupa abu dan pasir vulkan intermedier terdapat di daerah Kecamatan Kemalang, Manisrenggo, Prambanan, Jogonalan, Gantiwarno dan Wedi.

Adapun kondisi demografi, sesuai data Bappeda Klaten, jumlah penduduk pada tahun 2015 sebanyak 1.158 .795 jiwa dengan laju pertumbuhan $0,46 \%$ per tahun. Jumlah penduduk laki-laki pada tahun 2015 berjumlah 568.780 jiwa sedangkan perempuan 590.015 jiwa. Dari data tersebut jumlah penduduk perempuan lebih banyak dibandingkan dengan jumlah penduduk laki-laki. Wahidah Rustam (2015) menyatakan bahwa perempuan merupakan kelompok yang paling rentan ketika terjadi bencana. Perubahan iklim memiliki dampak yang dirasakan langsung oleh perempuan. Dalam rentang waktu lima bulan, dari Januari hingga Mei 2015 telah terjadi 881 bencana alam di berbagai wilayah di Indonesia. Terdapat keterkaitan yang erat antara bencana alam dan situasi ekonomi perempuan. Ketika bencana alam terjadi, banjir misalnya, maka perempuan petani juga perempuan nelayan akan kehilangan sumber ekonomi mereka. Jadi perubahan iklim sangat berpengaruh terhadap persoalan ekonomi sosial perempuan. Dari hasil kuisioner sejumlah 70 responden tersebar di seluruh wilayah Kabupaten Klaten didapatkan beberapa parameter tentang peran aktif perempuan di daerah rawan bencana, yaitu:

\section{a. Kabupaten Klaten termasuk daerah rawan bencana:}

Dari 70 responden yang menjawab daerah rawan bencana sebanyak 29 responden, sedangkan yang menjawab tidak rawan bencana sejumlah 41 responden. Menunjukkan bahwa pada wilayah di daerah Kabupaten Klaten tidak semua rawan terhadap bencana. Jika dilihat dari uraian di atas letak Kabupaten Klaten berada di antara Pegunungan Seribu dengan Gunung Merapi, maka Kabupaten Klaten termasuk daerah rawan bencana sedang. Letaknya yang sangat strategis di antara dua pegunungan menyebabkan daerah Kabupaten Klaten termasuk daerah yang subur tanahnya.

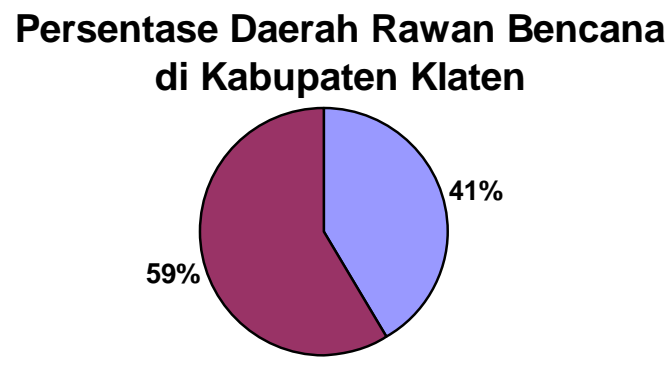

Rawan Bencana $\square$ Tidak Rawan Bencana

Gambar 1. Persentase Daerah Rawan Bencana Di Kabupaten Klaten 


\section{b. Jenis Bencana di Kabupaten Klaten:}

Dari 70 responden terdapat empat jenis bencana di Kabupaten Klaten, yaitu: Gempa Bumi 35 responden, Erupsi Merapi 15 responden, Banjir 20, dan Angin Ribut 5. Bencana yang sering terjadi di Kabupaten Klaten adalah banjir tetapi hanya di wilayah Klaten bagian selatan yang termasuk dalam aliran Sungai Dengkeng yang bermuara di Kabupaten Gresik. Daerah yang sering terjadi banjir tersebut karena letaknya termasuk dataran rendah dan merupakan aliran Sungai Bengawan Solo. Di mana pada daerah tersebut terjadi pendangkalan saluran juga dipicu banyaknya sampah yang berada di sungai tersebut.

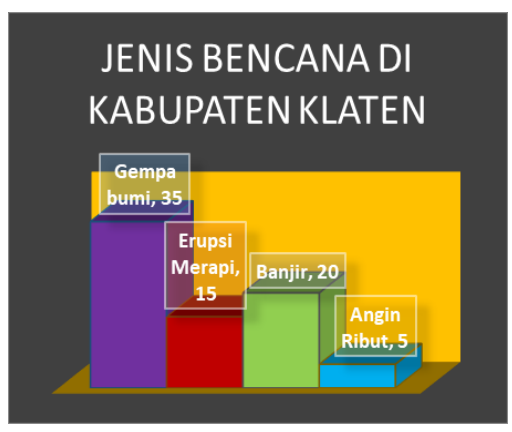

Gambar 2. Grafik Jenis Bencana Di Kabupaten Klaten

\section{c. Peran Aktif yang sudah pernah dilakukan selama ini:}

Dari 70 responden, 65 responden menyatakan ikut berperan aktif dalam membantu warga yang terkena bencana, sedangkan 5 responden menyatakan menyelamatkan diri. Dari pernyataan responden tersebut dapat dilihat bagaimana peran perempuan ketika bencana terjadi. Pendidikan tentang kebencanaan sudah mulai tertanam pada diri perempuan, khususnya di wilayah Kabupaten Klaten. Dari penjelasan para responden menyatakan peran aktif mulai dilakukan dan sangat dirasakan oleh mereka ketika terjadi bencana gempa bumi pada tahun 2006, 14 tahun yang lalu. Bagaimana mereka bahu membahu membantu tetangganya yang menjadi korban dari bencana tersebut. Bahkan para perempuan menjadi tukang masak di dapur umum yang dibangun oleh warga masyarakat di daerah tersebut. Mereka menceritakan bagaimana peran aktif para perempuan saat bencana tersebut terjadi. Ada yang ikut membersihkan puing-puing rumah tetangga yang menjadi korban gempa, ada yang ikut memasak di dapur umum, ada juga yang menjadi konseling untuk menenangkan keluarga yang menjadi korban gempa 2006.

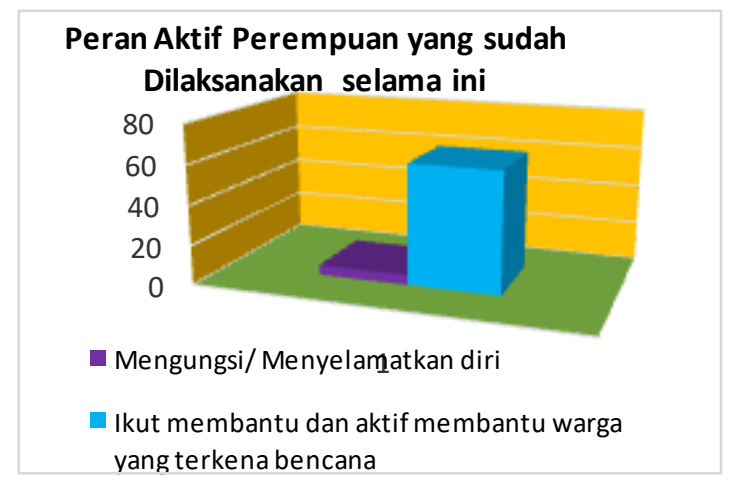

Gambar 3. Grafik Peran Aktif Perempuan yang Sudah Dilaksanakan Selama Ini 


\section{d. Solusi dalam Menghadapi Bencana}

Solusi yang ditawarkan responden ada 2 macam, yang pertama adanya Edukasi kepada warga masyarakat bagaimana kiat-kiat mengahadapi bencana, jika sewaktuwaktu bencana terjadi terdapat 18 responden, yang kedua menjaga lingkungan dari segala macam hal-hal yang dapat menyebabkan bencana, misal: tidak membuang sampah, melakukan penghijauan, perbaikan saluran yang mampet, mengolah sampah menjadi barang yang dapat dimanfaatkan kembali terdapat 52 responden.

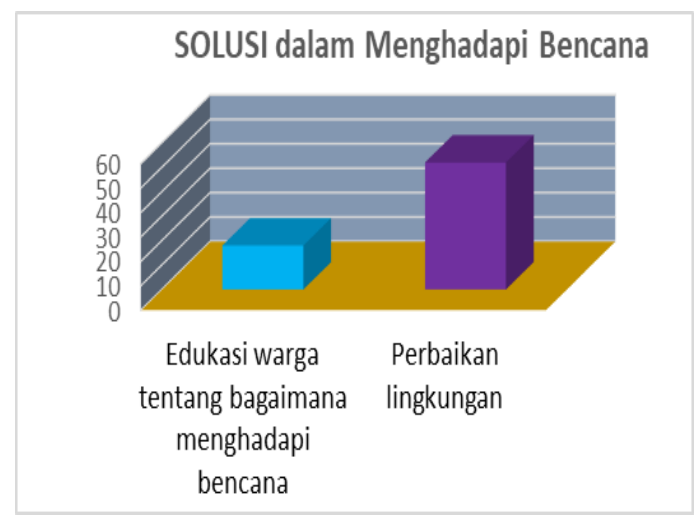

Gambar 4. Grafik Solusi dalam Menghadapi Bencana

\section{SIMPULAN}

Dari pembahasan di atas dapat diambil kesimpulan bahwa: Peran aktif perempuan di Kabupaten Klaten sudah mulai terlatih dan terbina dengan adanya sosialisasi baik dari aparat desa maupun kabupaten sendiri. Serta masih perlunya sosialisasi dan pembinaan kepada warga terutama perempuan di Kabupaten Klaten dalam rangka mengurangi resiko jika terjadi bencana.

\section{DAFTAR PUSTAKA}

Sadisun, 2007. Peran dan Fungsi Standard Operational Procedure (SOP) dalam Mitigasi Bencana Alam, Pusat Mitigasi Bencana ITB, Bandung

Wahidah Rustam, 2015. Perempuan adalah Korban Terbesar dari Berbagai Bencana yang Terjadi, Jurnal Perempuan 15 September 2015.

Hastuti, 2016. Peran Perempuan Dalam Menghadai Bencana Di Indonesia, Jurnal Geomedia, Volume 14 Nomor 2, November 2016. Retrieved from file:///C:/Users/ASUS/Downloads/13812-33975-1-PB.pdf

BNPB, 2017. Buku Saku Tanggap Tangkas Tangguh Menghadapi Bencana, Retrieved from https://siaga.bnpb.go.id/hkb/po-content/uploads/documents/Buku Saku10Jan18 FA.pdf

BSMI DKI Jakarta, 2019. Menyiapkan Perempuan Tangguh Bencana Dalam Keluarga. Srikandi Siaga Bencana (SSG), 21 Maret 2019. Retrieved from https://bsmidki.or.id/srikandi-siaga-bencana-menyiapkan-perempuan-tangguhbencana-dalam-keluarga/

Antara News Com, 2019. Perempuan-perempuan Tangguh di Tengah Bencana, 21 April 2019. Retrieved from https://www.antaranews.com/berita/838780/perempuan-perempuan-tangguh-ditengah-bencana

Antonius, M et al, 2019. Konsep Diri Perempuan di Kawasan Rawan Bencana Gunung Merapi, Jurnal ASPIKOM, Volume 4 Nomor 1, Juli 2019. Retrieved from file:///C:/Users/ASUS/Downloads/420-2554-1-PB\%20(2).pdf 
BNPB.go.id, 2019. Peran Penting Perempuan Dalam Kesiapsiagaan Bencana, 11 November 2019. Retrieved from https://siaga.bnpb.go.id/hkb/berita/peranpenting-kaum-perempuan-dalam-kesiapsiagaan-bencana

Solo Pos, 2020. Waspada 78 Desa Rawan Banjir Rawan Banjir di Klaten, 6 Januari 2020. Retrieved from https://www.solopos.com/waspada-ini-daftar-78-desarawan-baniir-di-klaten-1040155 